\title{
Numerical Analysis of Inducing Airflow Characteristics on the Airfoil Model Based Coanda Effect
}

\author{
Yaling Ye ${ }^{1, a}$, Xiaoyong Peng ${ }^{1, b *}$,Jingjing Liang ${ }^{1, c}$ and Zhiqiu Fu ${ }^{1, d}$ \\ 'Urban School of Construction,University of South China,Hunan,Hengyang,421001, China \\ ayeyalingtania@163.com, bpengxiaoyong@126.com, \\ cliangjingjing78@163.com, fzqiu42929346278@sina.com \\ ${ }^{*}$ Corresponding author.School of Urban Construction.University of South \\ China,Hengyang,421001, China. \\ Email Address:pengxiaoyong@126.com(Xiaoyong Peng).
}

\begin{abstract}
Keywords:Coanda effect,Inducing airfoil, Numerical simulation, Induction rate
Abstract.The flow fields of single airfoil model and symmetry airfoil model were simulated by CFD software in this paper. the different inducing velocity and the airfoil intervals were considered to study the flow field and the induction rate change of the models. The results show that the induction rates of the single airfoil model and the symmetry airfoil model enlarge when the inducing velocity increases, and gradually reaching a steady value. As interval of the symmetry airfoil model is increased, the induction rate increases. The air flow from the narrow slits of symmetry model can be mixed and disturbed each other.Therefore, the induction rate of symmetry airfoil model is not a simple superposition of the single airfoil model under the same inducing velocity. Induction rate and airfoil interval are the key factors to optimize the airfoil model.
\end{abstract}

\section{Introduction}

Fluid can change the direction of original flowing, and have a tendency along the convex surface of a object.According to Bernoulli Equation, due to the reducing velocity caused by friction between fluid and the surface the fluid flows through,fluid can be attached on the surface of the object when the object curvature is not too large. The phenomenon is called Coanda effect,which is applied to dust removal,drying and cooling replacing traditional air nozzle. And the method have saved 90 percent of the used amount of compressed air.Owing to the magnified effect of Coanda principle,the output air amount can be 20 to 25 times of the input amount[1].Bladeless fan is a successful application for Coanda effect, and an amount of studies focused on the research of characteristics of bladeless fan.For example,the numerical simulation about the influence of Coanda curvature and narrow outlet on the flow field characteristics[2-4]. There are also researches on discussing the factors about the slits inlet size and outlet dip on characteristics of bladeless fan[1,4].Coanda effect are applied to the aviation field, engineering, and the dynamics. The unmanned aerial vehicle ,circulation control airfoil, oil absorption technology and the frozen device are involving the application of Coanda effect.Coanda effect is being applied to the production process[5-8].Through the comparison between Fluent software numerical simulation and experimental,Peixing Li researched the factors on the injection uniformity of the galvanizing air knife jet , and put forward the relevant improving methods, which play a role in the uniformity of the coating[9].

In these studies, the study of airfoil induction rate impacted by airfoil induced spacing and induced velocity was rare based on Coanda effect. Air multiplier process induced by Coanda curve surface were simulated by the use of CFD in this paper, the airfoil flow characteristics and induction rate influenced by airfoils interval and inducing velocity were researched.

\section{Physical Models and Numerical Method}

Physical model.The 2-D airfoil model was built according to actual bladeless fan. Original point is located in narrow slit. The single airfoil model is consisted of narrow slits, Coanda curved surfaces and airfoil cap,and the length of the single airfoil model is $9 \mathrm{~cm}$,its width is $2.6 \mathrm{~cm}$, and the width of the 
narrow slit is $1.4 \mathrm{~mm}$. The single airfoil model is symmetric along the central axis of the model, which was placed in the flow field of $4700 \times 2000 \mathrm{~mm}$. As is shown in Fig 1.1. .Four different inducing velocities, $5 \mathrm{~m} / \mathrm{s}, 15 \mathrm{~m} / \mathrm{s}, 25 \mathrm{~m} / \mathrm{s}$ and $35 \mathrm{~m} / \mathrm{s}$ were chosen to analyze the impact of inducing velocity to induction rate of single airfoil model.
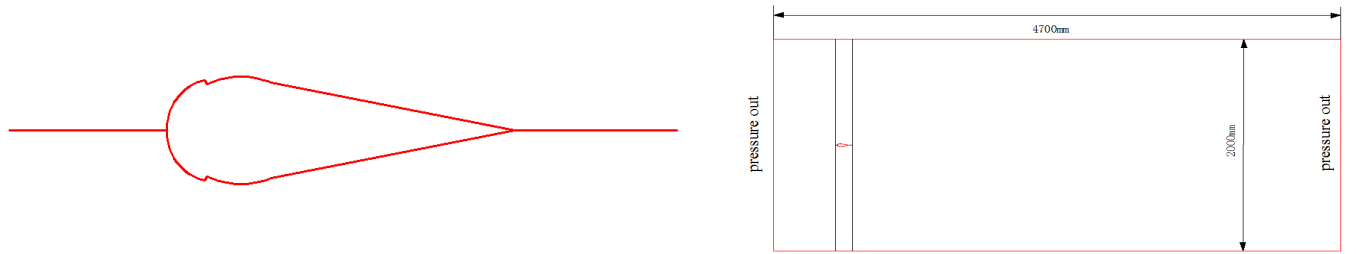

Figure1.1 Physical model and Computational domain of the 2-D single airfoil model

The symmetry airfoil model is composed of two half of single airfoil models, and the length of the flow field is $4700 \mathrm{~mm}$. The interval of the symmetry airfoil is alterable.As is presented in Fig 1.2.Four different airfoil intervals, $10 \mathrm{~cm}, 20 \mathrm{~cm}, 30 \mathrm{~cm}$ and $40 \mathrm{~cm}$ in corresponding inducing velocities were chosen to analyze the change of induction rate in the symmetry model.

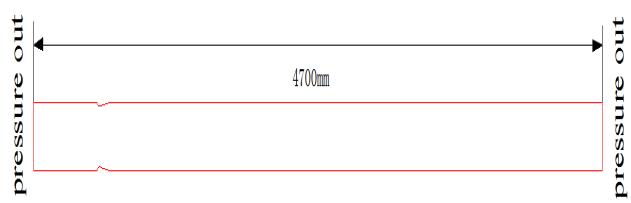

Figure 1.2 Physical model and Computational domain of the 2-D symmetry airfoil model

Numerical methods.Numerical methods of solving 2-D N-S equation on flow stability were used inducing the continuity equations and momentum conservation equations for flow properties.turbulence model is standard $\mathrm{K}-\varepsilon$ model, and the numerical method was SIMPLE algorithm. Mesh setting was Quad/Tri grid, the grids of the surrounding of Coanda curved surface and narrow slits were got local encryption, which aims to ensure precision, computational efficiency and the demand of the computer's memory.

\section{Single airfoil model}

Field distribution and Velocity contour.The streamline of the single airfoil model is presented to observe the real situation of the airflow in the whole field and surrounding airfoil, as shown in Fig 2.1.The streamline of the whole flow field is axisymmetric distributions along the airfoil center.inducing airflow from the narrow gap discharge attached to the Coanda curve surface.

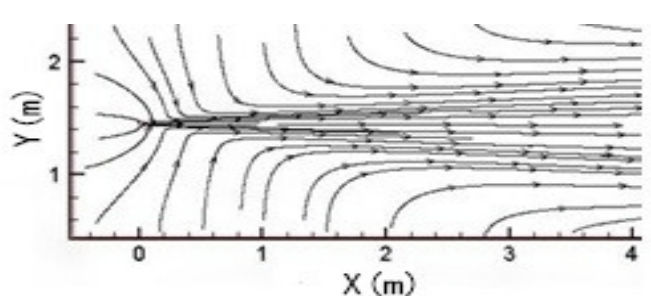

( a ) The streamline diagram of whole field

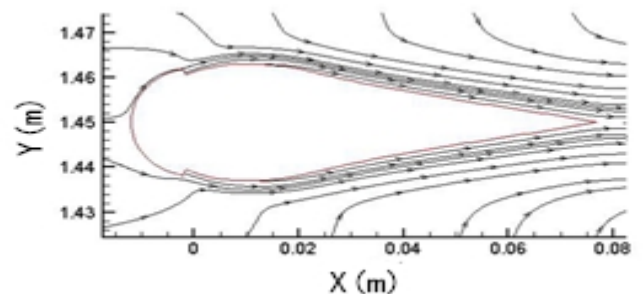

( $b$ ) The streamline diagram of partial field

Figure 2.1 The velocity contour of the single airfoil model

In order to conveniently observe the distribution of velocity, the velocity contours in the whole field and around the airfoil are shown in Fig 2.2 with the inducing velocity of $25 \mathrm{~m} / \mathrm{s}$. The velocity distribution of the whole field is symmetrical along the model central axis.the velocity-contour shape of extension of outlet is trumpet , and the opening become lager along the x positive axis.the velocity in the center of flow field is $2 \mathrm{~m} / \mathrm{s}$ at $\mathrm{x}=1 \mathrm{~m}$.. Velocity contour around the airfoil is strips, airflow is 
attached to Coanda curve surface, and velocity gradually decreases from inside to outside,the velocity on the both side of the airfoil is symmetric distribution in Fig 2.2(b).

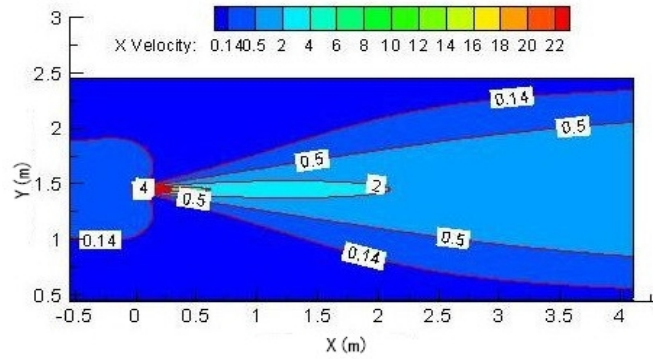

( a ) The velocity contour of whole field

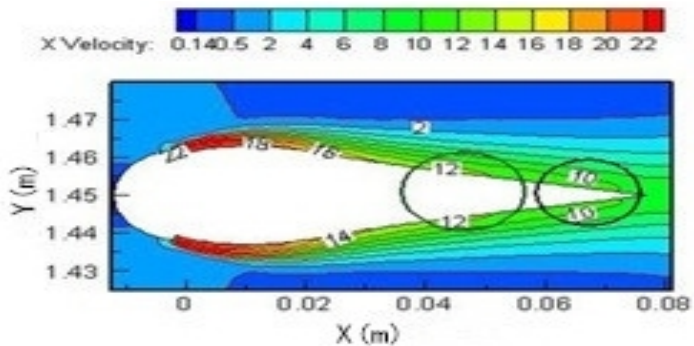

( b ) The velocity contour of partial field

Figure 2.2 The velocity contour of the single airfoil model

Induction rate.The induction rate of different model at $X=4 \mathrm{~m}$ were compared to shown the impact of inducing velocity and airfoil interval to induction rate with the inducing velocities of $5 \mathrm{~m} / \mathrm{s}$, $15 \mathrm{~m} / \mathrm{s}, 25 \mathrm{~m} / \mathrm{s}$ and $35 \mathrm{~m} / \mathrm{s}$, as shown in Fig 2.3. With the increase of inducing velocity, the induction rate enhances and finally reaches steady state, and the growth of induction rate slowed. When the inducing velocity increases to $25 \mathrm{~m} / \mathrm{s}$, the induction rate keep a steady value,.After that, induction rate little change as the increase of speed.

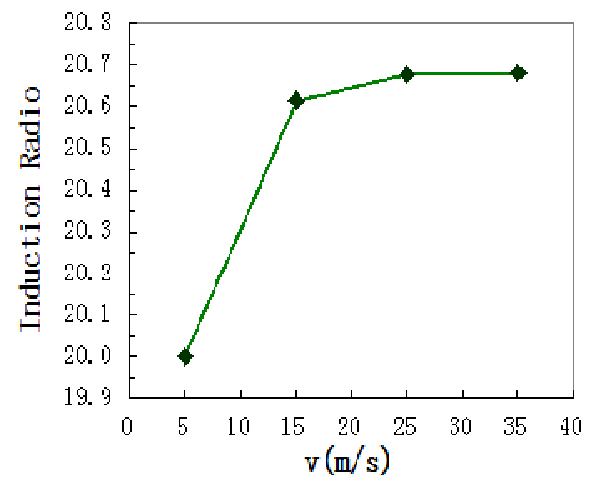

Figure 2.3 The induction rate of single airfoil model in different induced velocity

\section{Symmetry airfoil models}

Flow field and Velocity contour.The streamlined pattern of symmetry model in whole and local flow field are presented in Fig 3.1 to observed the specific situation of the airflow. The streamline of the whole flow field is symmetrical distribution along the axisymmetric center; Inducing airflow from airfoil slit discharge attached along the Coanda surface, and inducing external airflow to the direction of inducing air.

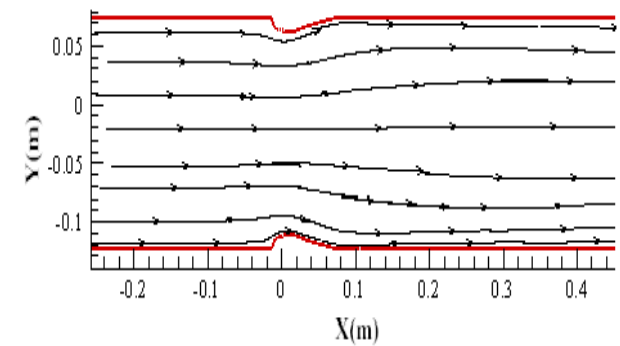

( a ) The whole field streamline diagram

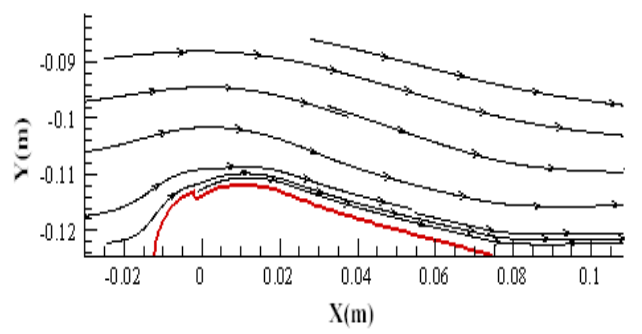

( $b$ ) The partial field streamline diagram

Figure 3.1 Symmetry airfoil models streamline diagram

The velocity contour in whole flow field and around the airfoil are shown in Fig 3.2 to observe the distribution of velocity with the inducing velocity of $25 \mathrm{~m} / \mathrm{s}$. Velocity contour around the airfoil is strips, airflow is attached to Coanda curve surface, and gradually decreasing from inside to 
outside.the velocity in the center of flow field is $3 \mathrm{~m} / \mathrm{s}$ at $\mathrm{x}=1 \mathrm{~m}$.. Induced external airflow on the two half of airfoils develop along the direction of inducing air.Velocity partition also has developed from two single distributions into an integral whole. The area between the two half airfoils have a low speed region, suggesting that inducing velocity and the interval between two airfoils have a great influence on induction rate, the most of airflow attach to Coanda curve surface to develop, and mixing degree also reduce in the middle of the airflow.

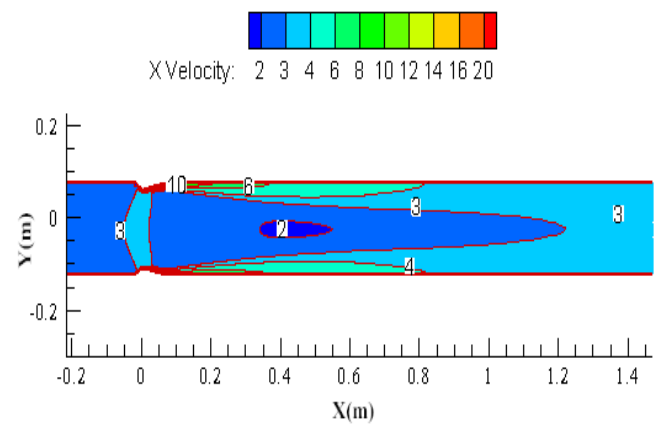

( a ) The whole field velocity contour

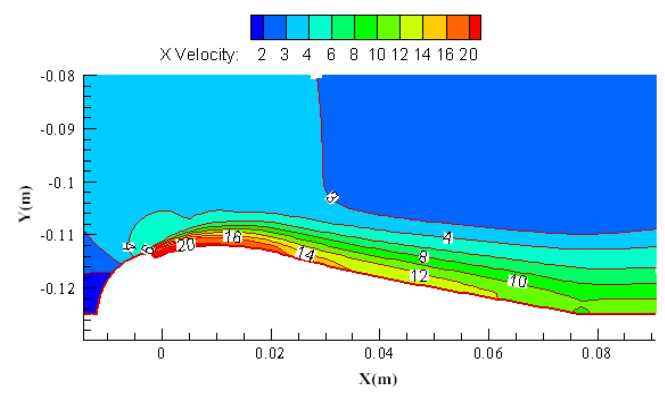

( b ) The partial field velocity contour

Figure 3.2 Velocity contour of symmetry airfoil model

Induction rate.Inducing velocities and the intervals between airfoils is considered to impact induction rate, the different models are chosen to analyze their induction rates at $X=4 \mathrm{~m}$, as shown in Fig 3.3. when inducing velocity is a constant, the model induction rate increases following the airfoil interval enlarging. When the airfoil interval is $10 \mathrm{~mm}$, the induction rate is maximum when inducing velocity is $15 \mathrm{~m} / \mathrm{s}$, When airfoil interval is greater than or equal to $20 \mathrm{~mm}$ and inducing velocity increase to $25 \mathrm{~m} / \mathrm{s}$, the induction rate reach to a steady value gradually.

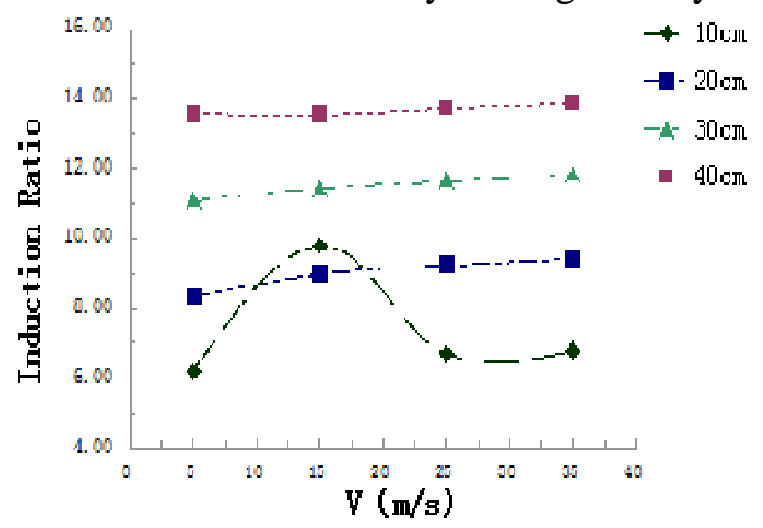

Figure 3.3 The induction rate of the symmetry airfoil models under different induction velocities and intervals

\section{Conclusion}

The 2-D models of the single airfoil and symmetric airfoil were performed in this paper, which was to attain the influence of inducing velocity and the airfoil interval on induction rate.

(1) When inducing velocity is $25 \mathrm{~m} / \mathrm{s}$, the induction rate can reach to a steady value for the single airfoil model and the symmetry airfoil model except the induction rate keep a small variation with the inducing velocity exceeding $25 \mathrm{~m} / \mathrm{s}$.

(2) For the symmetry airfoil model, there are a positive correlation between the induction rate and the interval of two airfoils when the velocity is a constant.The optimal inducing velocity is 15 $\mathrm{m} / \mathrm{s}$, when the airfoil interval is $10 \mathrm{~mm}$.

(3) Because of the airflow mixing between airfoils, the induction rate of symmetric airfoil model is not increased simply with times comparing to the single model.But the same velocity line can develop further for symmetry model than single airfoil model. 


\section{Reference}

[1]Information on http://blog.sina.com.cn/s/blog_49a6df3a0100zr2q.html.

[2]Hanxiang Wang,Min Zhan,Haizhen Xu.Analysis and optimization on outlet of bladeless fan. Journal of Micromachined Fluid(In Chinese),2013,41(15):19-20.

[3]Guoqi Li. Influence of Coanda surface curvature on performance of bladeless fan.Journal of Thermal Science, 2014,23(5):422-431.

[4]Guangxing Zhang.Study on the characteristic of flow field and air supply of bladeless fan(In Chinese).Hangzhou:Zhejiang Sci-Tech University,2013.

[5] Zhenyun Liu .aircraft with Coanda effect(In Chinese). Journal of Applied Science, 2010,37(10):67.

[6] Shiyu Zhang.The study about the dynamic supercharging technique of circulation control airfoil(In Chinese).Nan Jing: Nanjing University of Aeronautics and Astronautics.(2011)

[7] Xunchong Feng.the oil absorption technique application about coil edge of cold rolling aluminum(In Chinese). China High Technology Enterprises,2013,266(23):33-35.

[8] Zhen Zhang.The numerical simulation of airflow and temperature field for quick-frozen equipment with up-down perforated plates(In Chinese).Journal of Refrigeraten,2009,30(5):36-40.

[9]Peixing Li.The improvement research about the uniformity galvanized coating with steal materials(In Chinese).Anshan:University of Science and Technology Liaoning,2014. 